\title{
Strategi pemasaran pada the ritz carlton spa nusa dua bali
}

\author{
Ni Wayan Anik Swandewi'), Agung Sri Sulistyawati' ${ }^{2)}$,Ni Ketut Arismayanti ${ }^{3)}$ \\ Fakultas Pa riwisa ta \\ anicswandewi@yahoo.com ${ }^{1)}$
}

\begin{abstract}
Abstrak
Penelitian ini dila tar belakangi kunjungan wisa tawan yang tidak memenuhi target bebe rapa tahun seperti tahun 2015 dan tahun 2017 serta presentase kunjungan wisa tawan yang menginap di hotel pun sangat minim meskipun telah dilakukan beberapa promosi-promosi penjualan. Tingginya rata-rata occupancy hotel tidak menjadikan semua wisa tawan yang menginap di The Ritz Carlt on Hotel berkunjung ke spa. Pada tahun 2015, terdata hanya 29,7\% wisa tawan y ang men ginap di hotel The Ritz Carlton dari total occupancy hotel yang mengujungi spa. Pa da tahun 2016 terdata $6,6 \%$, tahun 2017 terdata $5,9 \%$ dan tahun 2018 terdata $6,7 \%$ dari total occupancy yang mengunjungi spa. Ditambah lagi dengan sedikitnya kunjungan wisa tawan dariluarhotel ke spa. Mengingat dari hotel berbin tang lima la innya di kawasan Sawangan, The Ritz Carlton hotel masih tergolong baru. Penelitian ini bertujuan untuk mengetahui lingkungan internal dan eksternal sert a strategi pemasaran spa The Ritz Carlton Spa.

Teknik a nalisis da ta yang digunakan dalampenelitian ini a dalah dengan a nalis is deskriptif kua litatif dan analisis SWOT dibantu dengan teknik skala Likert. Teknik pengumpulan data didapatkan dari hasil observasi, wa wancara, kuesioner, stu di kepustakaan d an dokumentasi. Teknik penentuan informan yang digunakan yaitu Purposive Sampling. Teknik Pengambila n sa mpel menggunakan rumus Slovin berjumlah 100 orang responden dengan accidental sampling seba gai penyebaran kuesionernya.

Ha sil penelitian menyatakan bahwa lingkungan internalberisi segmenting, targeting dan positioning serta bauran pemasaran 9P. Lingkungan eksternal berisi faktor politik, hukum, ekonomi, sosial bu daya, teknologi dan lingkungan media. Stra tegi SO a dalah stra tegi menciptakan progra m treatment baru a tau program healing berbasis tradisibudaya Bali. Stra tegi WO yakni strategi peningkatan kualitas SDM agar dapat memberikan pelayanan maksimal. Strategi ST leb ih memperkenalkan brand The Ritz Carlton Spa. Strategi WT adalah memperbaiki kualit as produk dan jasa agar dapat bersaing di pa saran.
\end{abstract}

Kata Kunci: Strategi, Pemasaran, Spa, Hotel

\begin{abstract}
This research is motivated by tourist visits that do notmeet the target of several years such as 2015 and 2017 and the percentage of tourist visits staying at hotels is also very min imal despite several sales promotions. The high average hoteloccupancy does not make all tourists staying at The Ritz Carlton Hotel visit the spa. In 2015, only 29.7\% of tourists stayed at The Ritz Carlton hotel out of the total hotel occupancy that visited the spa. In 2016 recorded 6.6\%, in 2017 recorded $5.9 \%$ and in 2018 recorded $6.7 \%$ of the total occupancy who visited the spa. Along with the lack of tourist visits from outside the hotel to the spa. Considering that other five-star hotels in the Sawangan area, The Ritz Carlton hotel is still relatively new. This study aims to determine the internal and external environment and marketing strategies of The Ritz Carlton's Spa.

The data analysis technique used in this study was qualita tive descrip tive analys is and SWOT analysis was assisted by a Likert scale technique. Data collection techniques are obtai ned from the results ofobservations, interviews, questionnaires, literature studies and documentation. The informant determination technique used is Purposive Sampling. The sampling technique uses the Slovin formula totaling 100 respondents with accidental sampling as the distribution of the questionnaire.

The results of the study stated that the internal environment contained $9 P$ se gmenting, targeting and positioning as well as the marketing mix. The external environment contains political, legal, economic, socio-cultural, technological and media environment factors. The SO strategy is a strategy for creating new treatment programs or healing prog rams based on Balinese cultural traditions. WO strategy is a strategy to improve the quality of human resources in order
\end{abstract}


to provide maximum service. The ST strategy further introduces the Ritz Carlton Spa brand. WT's strategy is to improve the quality of products and services in order to compete in the market.

Keywords: Strategies, Marketing, Spa, Hotel

\section{PENDAHULUAN}

Sektor pariwisata merupakan sektor yang potensial untuk di kembangkan sebagai salah satu sumber pendapatan daerah dengan membuka lapangan pekerjaan bagi masyarakat setempat, yang tentunya mampu menaikkan taraf hidup masyarakat Bali. Pulau Bali telah dikunjungi oleh wisatawan dari berbagai Negara di seluruh dunia. Karena dengan melaksanakan aktivitas kepariwisataan dapat meningkatkan daya kreativitas, mengurangi kejenuhan kerja, membuka wawasan mengenai suatu budaya, relaksasi, mengetahui peninggalan yang berhubungan dari suatu bangsa, serta melakukan bisnis (Wiyasa, 1997). Menurut Jaya Pramono (2012), meningkatnya semangat multikultur dunia yang memunculkan pengakuan adanya persamaan warna kulit, hak ekonomi, hak sosial, hukum dan lainnya, yang berdampak pada timbulnya keinginan untuk mengalami relaksasi, untuk mengurangi depresi, stress, serta menciptakan sebuah gaya hidup yang bersemangat dan menyenangkan atau mencoba keluar dari rutinitas harian yang ada. Kondisi inilah yang menciptakan bertumbuhnya kegiatan wellness and spa sangat dicari oleh wisatawan.

The Ritz Carlton Hotel Nusa Dua merupakan salah satu hotel berbintang lima yang ada di Kabupaten Badung. The Ritz Carlton Hotel berdiri di tanah seluas 12.7Ha. Berdasarkan pendiri awalnya, Horst Schulze, Herve Humler dan William B. Johnson, The Ritz Carlton Company memiliki tradisi yakni "luxury surrounding throughout property". Salah satu fasilitas luxury yang ditawarkan The Ritz Carlton Hotel adalah fasilitas spa yang merupakan tempat favorite wisatawan untuk relaksasi. The Ritz Carlton memberikan beberapa fasilitas tambahan untuk melengkapi Spa yakni Wet facilities, Fitness center, Yoga, Muse Hair Salon dan Gift Shop.

Jumlah kunjungan wisatawan ke The Ritz Carlton Spa pada tahun 2015 dan 2017 tidak memenuhi target bahkan dengan tingginya rata-rata occupancy hotel tidak menjadikan semua wisatawan yang menginap di The Ritz Carlton Hotel berkunjung ke spa. Pada tahun 2015, terdata hanya 29,7\% wisatawan dari dalam hotel The Ritz Carlton dari total occupancy hotel yang mengujungi spa. Pada tahun 2016 terdata 6,6\%, tahun 2017 terdata 5,9\% dan tahun 2018 terdata 6,7\% dari total occupancy yang mengunjungi spa. Ditambah dengan sedikitnya kunjungan wisatawan dari luar hotel mengingat Nusa Dua adalah area exclusive dengan deretan hotel berbintang lima. The Ritz Carlton Hotel bukanlah satu-satunya hotel yang menawarkan fasilitas spa dengan keunikannya. Hotel berbintang lima lain berlomba-lomba untuk meningkatkan kunjungan wisatawan dengan memberikan pelayanan yang baik dan membuat berbagai macam promosi. Atas dasar kunjungan wisatawan yang sedikit dari dalam maupun luar hotel maka penelitian ini bermaksud meneliti pemasaran yang dilakukan dan strategi pemasaran yang dapat dilakukan dengan tujuan untuk memaksimalkan pemasaran dan pelayanan serta meningkatkan kunjungan wisatawan ke spa.

\section{METODE PENELITIAN}

Pada penelitian ini sampel yang dipakai adalah 100 orang, dasar pengggunaan 10\% karena merupakan angka yang cukup ideal dan sederhana perhitungannya dari yang telah dijelaskan. Selain itu juga karena mempertimbangkan waktu dan dana yang ada pada penelitian ini.Berdasarkan perumusan tersebut, penelitian ini akan melakukan pembagian kuesioner kepada 100 responden. Teknik pengambilan sampel yang digunakan dalam penelitian ini adalah accidental sampling. Analisis data dalam hal ini bersifat deskirptif kualitatif, menurut Astina, (2002:50) analisis deskriptif kualitatif yaitu data yang telah terkumpul berbentuk kata atau kalimat yang diperoleh dari berbagai sumber baik dari hasil wawancara mendalam atau pengamatan secara langsung di lapangan dan kajian 
pustaka disusun ke dalam teks yang telah di analisis melalui interpretasi guna memperoleh makna.

\section{HASIL DAN PEMBAHASAN}

\subsection{Lingkungan Internal :}

\section{Segmenting}

Tabel 3.1, Segmenting The Ritz Carlton Spa

\begin{tabular}{|c|l|l|}
\hline Variabel & \multicolumn{1}{|c|}{ Indikator } & \multicolumn{1}{c|}{ Pembahasan } \\
\hline \multirow{4}{*}{ Segmenting } & 1) Segmentasi berdasarkan geografi & $\begin{array}{l}\text { Wisa ta wan asal Australia, Asia, Eropa } \\
\text { Amerika dan Afrika }\end{array}$ \\
\cline { 2 - 4 } & 2) Segmentasi berdasarkan demografi & Wisa ta wan berumur 17 tahun ke atas \\
\cline { 2 - 4 } & 3) Segmentasi berdasarkan psikografi & - \\
\cline { 2 - 3 } & 4) Segmentasi berdasarkan tingkah laku & - \\
\hline
\end{tabular}

Sumber: Da ta diolah, (2019).

Pertimbangan psikografi dan pertimbangan tingkah laku tidak dilakukan oleh The Ritz Carlton Spa karena sikap dan gaya hidup seseorang yang menginap di Ritz Carlton Hotel sudah dapat dipastikan mengingat Ritz Carlton merupakan hotel berbintang lima di Bali dengan harga kamar dan spa khususnya yang tidak murah.

\section{Targeting}

Target pasar Asia dan Eropa khususnya honeymooner lalu family guest dan group meeting atau group spa. Hal ini dikarenakan fasilitas lengkap yang dimiliki oleh hotel sendiri sangat cocok untuk wisatawan target spa. Honeymooner yang biasanya hanya ingin berada di dalam hotel dan melakukan couple treatment. Untuk wisatawan yang datang dengan keluarga dan anak-anak pun sangat disarankan karena fasilitas The Ritz Kids yang dimiliki oleh bisa menjadi tempat bermain yang disukai anak-anak. Selain itu target pasar Asia dan Eropa dipilih karena banyaknya kunjungan wisatawan asal benua tersebut (lihat karakteristik wisatawan berdasarkan Negara Asal). Tingkat persaingan pasar dapat dihadapi dengan keunikan perawatan dan fasilitas yang ditawarkan oleh spa yakni perawatan Indian Ocean Ritual dan pelayanan ramah dan cepat yang diberikan oleh staff untuk mencapai kepuasan wisatawan.

\section{Positioning}

Posisi pasar atau image yang diciptakan oleh The Ritz Carlton Spa adalah sesuai dengan image yang diciptakan oleh hotelnya sendiri yakni luxury spa dengan tema the source of life Bali. Image ini dipilih karena terinspirasi dari Indian Ocean yang menjadi sumber kehidupan di Bali yang terlihat pada kebanyakan ritual upacara keagamaan di Bali terpusat pada air dan laut. Kegiatan pendukung untuk citra ini adalah dari pagi hari dimulai dengan mebanten pada pagi hari, tradisional musik rindik yang dapat ditemui di lobby The Ritz Carlton, surf initiation class, everyday morning sunrise yoga class, melayangan atau kite runner dan jajanan yang dibuat dari bahan kelapa.

\section{Bauran Pemasaran 9P}

1) Product, The Ritz Carlton Spa menawarkan perawatan massage, facial, body wrap scrub, soaking ritual, The Ritz Carlton Spa Signature Massage. Fasilitasnya yakni wet facilities, single room treatment, villa spa treatment, retail shop, fitness center, yoga studio, Balinese bathing pool, Prana relaxation room, soul purification and sarong concierge. 
2) Price, harga yang ditawarkan The Ritz Carlton Spa berkisar untuk perawatan yang paling murah seharga Rp. 500.000 untuk aromateraphy bath dan paling mahal seharga Rp. 4.800 .000 untuk perawatan dengan pasangan. Harga ini belum termasuk $21 \%$ tax and service.

3) Place, saluran distribusi secara langsung adalah melalui sosial media dan media online langsung dari wisatawan ke staff spa sedangkan saluran distribusi secara tidak langsung adalah melalui travel agent melalui pihak ketiga.

4) Promotion, promosi melalui promosi penjualan seperti melalui sales call, promosi melalui iklan secara online social media, website dan melalui majalah, promosi melaui penjualan yang dilakukan perorangan yakni staff The Ritz Carlton Spa dengan product knowledge yang dimiliki, selanjutnya promosi melalui hubungan baik dengan masyarakat yakni dengan melakukan bersihbersih pantai sebulan sekali dan menjadi donator di Yayasan Panti Asuhan Yayasan Hati Mama.

5) Process, proses dari pemesanan perawatan yang cepat, check in dengan welcome drink, proses perawatan yang dilakukan terapis handal dan proses check out dengan complimentary beverage dan proses pembayaran yang cepat.

6) People, staff The Ritz Carlton Spa yang menggunakan tata cara berbahasa dan bersikap sesuai dengan SOP. Pengetahuan tentang product knowledge adalah hal yang harus dimiliki semua staff hotel.

7) Physical Evidence, Bangunan fisik spa dikelilingi dengan tanaman dan kolam yang memperlihatkan konsep luxury. Terinspirasi oleh The Lost City of Petra di Jordan dimana kita bisa menggambar kesamaan yang sejajar sambil menggabungkan unsur-unsur asli dengan sentuhan modern dan kontemporer, sejalan dengan arsitektur hotel keseluruhan.

8) Packaging, paket spa yang ditawarkan tidaklah banyak dan hanya ditawarkan pada hari-hari tertentu seperti Imlek, Tahun Baru, Hari Natal.

9) Payment, cara pembayaran di The Ritz Carlton spa sangatlah mudah menggunakan cash, credit card maupun room charge.

\subsection{Lingkungan Eksternal}

1. Faktor hukum dan politik, Samantha Brown, wisatawan asal Australia dalam wawancara tanggal 15 Mei 2019 mengatakan pendapatnya mengenai visa dan KITAS (surat izin tinggal sementara):

"I don't think it takes a long time just to get holiday visa to Bali. You can take maximum 30 days and extend it. Or as Indonesia gives some nationality free visa as you can pay it when you arrived at the airport. It's only USD 30 or something but you can't extend it. For KITAS, it takes months to get it, some document or your government make it complicated. But it is harder for Indonesian to get visa to Australia then us, Australian to come here, so I am not really complaining."

Hasil wawancara dengan akademisi Ibu Made Wendri (akademisi) pada tanggal 22 Juli 2019 mengatakan bahwa :

'seharusnya pemerintah lebih mengumumkan tentang jaminan kesehatan bagi konsumen, agar tidak terjadi mal praktek sehingga wisatawan tahu manfaat dari fasilitas dasara dari PerMenKes No. 8 tahun 2014.'

Namun dalam bisnis.com (penulis Satrya, Dosen Hotel \& Tourism Business Fakultas Pariwisata Universitas Ciputra Surabaya, tanggal 04 Januari 2018) menuliskan bahwa faktor utama yang mempengaruhi situasti pasar valuta dan saham adalah dinamika politik menuju pilpres yang terkesan tidak kondusif. Nilai tukar rupiah sudah tembus Rp. 14,000 sampai hari ini. Selain itu keamanan saat pemilihan presiden membuat wisatawan 
berpikir untuk datang ke Bali, takut adanya demo dan aksi yang akan mempengaruhi keamanan wisatawan. Untuk wisatawan domestic sendiri, potensi penurunan akitivitas belanja saat berwisata disebabkan secara psikilogis saat wisatawan hendak keluar dari hotel untuk bepergian. Pada masa kampanye yang cenderung diisi dengan pengumpulan massa, konvoi kendaraan serta pengerahan massa yang dilakukan partai politik yang ditakuti wisatawan juga kerap mengganggu lalu lintas.

2. Faktor ekonomi, Perkembangan industri pariwisata ditujukan untuk meningkatkan pendapatan daerah dan Nasional dalam rangka membuat dan memperluas kesempatan bekerja dan lapangan pekerjaan. Hal ini diharapkan untuk meningkatkan kesejahteraan dan kemakmuran masyarakat, memperkenalkan dan memperdayakan obyek daya tarik wisata di Indonesia, Bali khususnya.

Hasil wawancara dengan Ibu Wendri pada tanggal 22 Juli 2019, beliau mengatakan bahwa :

'perkembangan usaha wellness di Bali sangat menjanjikan, produk berlimpah sehingga senantiasa berpeluang dengan nuansa yang bervariatif, berbeda dengan sajian negara lain'.

3. Faktor sosial budaya, Bali yang disebut living museum karena tidak ada pariwisata pun, masyarakat Bali tetap menjalankan segala aktivitas adat dan religi yang membuat Bali sebagai salah satu destinasi wisata budaya.

"I don't think Bali should take more people to come because well, this is a bit crowded already. Look at the traffic jam. When I first come here, Bali is still a little green and traffic only cause by huge ceremony. Now, I understand they wanted to develop but they need to think about limit as well. Maybe make more public transport more like in Jakarta and more traffic lights" (Samantha Brown, 15 Mei 2019).

Pariwisata memang membuka banyak lapangan pekerjaan untuk usia yang ditentukan serta membantu kesejahteraan masyarakat namun pemerintah dan masyarakat juga harus memikirkan tentang keberlanjutan pariwisata agar tidak mengikis daerah hijau dan membuat polusi meningkat.

4. Faktor teknologi, teknologi membuat segalanya lebih cepat dan mudah. Diawali dengan pemesanan, check in, check out dan pembayaran dengan mudah. Kemajuan teknologi juga sangat menghemat biaya promosi dan pemasaran.

5. Faktor lingkungan media, media dapat memberikan kesan yang positif dan meningkatkan kunjungan wisatawan ke spa namun media juga dapat memberi kesan negatif atas satu perusahaan dan melalui media online, kesan negatif ini sangat cepat menyebar dan dilihat oleh wisatawan, maka dari itu perusahaan harus berhati-hati.

\subsection{Strategi Pemasaran The Ritz Carlton Spa}

Berdasarkan hasil analisis SWOT yang menguraikan tentang kekuatan (strength), kelemahan (weakness), peluang (opportunities) dan ancaman (threat) yang dimiliki oleh The Ritz Carlton Spa maka dapat dikemukan strategi pemasaran yang dapat diterapkan pada The Ritz Carlton Spa dapat dilihat pada Tabel 3.2 
Tabel3.2, Analisis Matriks SWOT Pemasaran The Ritz Carlton Spa

\begin{tabular}{|c|c|c|}
\hline & Kekuatan/Strenght $(S)$ & Kelemahan/Weaknesses $(W)$ \\
\hline $\begin{array}{l}\text { EFAS } \\
\text { (External Factor } \\
\text { Analysis Strategy) }\end{array}$ & $\begin{array}{l}\text { S1. Keragaman treatment dan fasilitas } \\
\text { lengkap } \\
\text { S2. Keunikan treatment Indian Ocean Ritual } \\
\text { S3. Minyak / oil treatment khas The Ritz } \\
\text { Carlton Spa } \\
\text { S4. Welcome drink dan check out beverage } \\
\text { S5. Kebersihan spa } \\
\text { S6. Akses dan lokasi spa yang strategis } \\
\text { S7. Reservasi, check in, check out yang cepat } \\
\text { dan mudah } \\
\text { S8. Penampilan staff yang baik dan ramah } \\
\text { S9. Lingkungan dan arsitektur bangunan spa } \\
\text { S10. Cara pembayaran yang mudah }\end{array}$ & $\begin{array}{l}\text { W1. Kura ngnya potongan harga } \\
\text { W2. Harga treatment spa yang mahal } \\
\text { W3. Tidak a da fasilitas transport bagi } \\
\text { outside guest } \\
\text { W4. Iklan spa hanya melalui online } \\
\text { W5. Kurangnya staff y ang bisa berbahasa } \\
\text { a sing lain sela in Ba hasa Inggris } \\
\text { W6. Kurangnya paket spa yang menarik }\end{array}$ \\
\hline Peluang/Opportunities $(O)$ & Strategi SO (Strength Oppotunities) & Strategi WO $(W$ \\
\hline $\begin{array}{l}\text { O1. Bera da didaerah ekslusif hotel } \\
\text { dan jauh dari kepadatan dan } \\
\text { titik kemacetan } \\
\text { O2. Kemajuan teknologi informasi } \\
\text { dan komunikasi } \\
\text { O3. Budaya dan tradisi Baliyang } \\
\text { menarik } \\
\text { O4. Pantai yang menjadi } \\
\text { pemandangan utamahotel } \\
\text { O5. Keamanan Bali yang kondusif }\end{array}$ & $\begin{array}{l}\text { 1. Strategi menciptakan program } \\
\text { treatment baru atau program healing } \\
\text { berbasis tradisi budaya Bali (S1,S2, } \\
\text { S3, S4, O3, O4); } \\
\text { 2. Strategimemaksimalkan tekn ologi } \\
\text { dengan lokasi strategis, pela yanan } \\
\text { dan proses yang cepat(S5, S6, S7, } \\
\text { S8, S9, S10, O1, O2, O5). }\end{array}$ & $\begin{array}{l}\text { 1. Strategi peningkatan kualitas SDM } \\
\text { agar dapat memberikan pelayanan } \\
\text { maksimal(W5,O3,O5); } \\
\text { 2. Strategi penambahan paket - paket } \\
\text { spa yang menarik dengan harga } \\
\text { bersaing(W1,W2,W3, O4,); } \\
\text { 3. Strategi peningkatan promosi dan } \\
\text { publikasi secara online maupun } \\
\text { offline (W4, O1, O2). } \\
\text { 4. Strategi nilai tambah produk (W1, } \\
\text { W2,O3). }\end{array}$ \\
\hline Ancaman /Threats (T) & Strategi ST (Strength Threats) & Strategi WT (Weakness Threats) \\
\hline $\begin{array}{l}\text { T1. Kompetitor spa dihotel ber- } \\
\text { bintang lima pada kawasan } \\
\text { yang sama } \\
\text { T2. Bencana alam erupsi Gunung } \\
\text { Agung } \\
\text { T3. Kurangnya kompetensi terapis } \\
\text { Bali } \\
\text { T4. Daya beli konsumen menurun } \\
\text { T5. Daily Spa dengan harga lebih } \\
\text { murah }\end{array}$ & $\begin{array}{l}\text { 1. Strategi lebih memperkuat brand } \\
\text { The Ritz Carlton Spa ( S1, S2, S3, } \\
\text { S4, S5, T1, T3); } \\
\text { 2. Strategimemperkuat pangsa pasar ( } \\
\text { S6, S7, S8, T2, T4); } \\
\text { 3. Strategi penerapan harga yang } \\
\text { dinamis atau bersaing untuk } \\
\text { menghadapi persaingan (S2, S9, } \\
\text { T5). }\end{array}$ & $\begin{array}{l}\text { 1. Strategi memperbaiki kualitas produk } \\
\text { dan jasa agar dapat bersaing di } \\
\text { pasaran(W1, W2, W3, W6, T1, T3, } \\
\text { T4, T5); } \\
\text { 2. Stra tegi meningkatkan kerjasama } \\
\text { dan menjaga hubungan baik dengan } \\
\text { departemen lain di hotel dan travel } \\
\text { agent online maupun offline (W4, } \\
\text { W5, T2). }\end{array}$ \\
\hline
\end{tabular}

Sumber : Hasil Penelitian, (2019).

Berdasarkan Tabel 3.2 di atas maka didapatkan 4 (empat) langkah alternatif strategi The

Ritz Carlton Spa sebagai berikut :

1. Strategi SO (Strength Opportunities)

Strategi ini dibuat berdasarkan jalan pikiran perusahaan, yaitu dengan memanfaatkan seluruh kekuatan yang dimiliki The Ritz Carlton Spa untuk merebut dan memanfaatkan peluang sebesar-besarnya. Untuk strategi pertama yakni strategi menciptakan program treatment baru atau program healing berbasis tradisi budaya Bali, berikut program - program yang dapat diterapkan adalah : 
1) Membuat program 60 minutes Balinese healing ritual dengan mendatangkan Balinese priest (pemangku). Urutan ritual healing adalah dimulai dengan berbicara masalah, bermeditasi, pengobatan dengan batu suci, sembahyang dan diberi tirtha.

2) Memanfaatkan wangi - wangian khas dari Bali seperti kayu cendana dan Bunga kenanga untuk treatment baru. Kombinasi dari 45 minutes Balinese massage dan 15 minutes aromateraphy bath.

3) Menambahkan 'after treatment beverage' pada keunikan treatment Indian Ocean Ritual yakni minuman yang berbahan hasil laut seperti jus rumput laut \& seaweed cookies.

Selanjutnya program-program yang dapat diterapkan guna menjalankan strategi memaksimalkan teknologi dengan lokasi strategis, pelayanan dan proses yang cepat adalah sebagai berikut:

1) Memanfaatkan lokasi dan akses yang baik untuk mendapatkan income tambahan dengan bekerja sama dengan armada transport yang sudah dimiliki dan menerapkan tarif terjangkau yang akan mempermudah wisatawan.

2) Mempertahankan sistem hotel yang mencatat dan menyimpan jika ada tamu repeater sehingga kita dapat melihat apa yang disukai dan tidak disukai wisatawan agar mempermudahkan pelayanan guna mencapai kepuasan wisatawan.

3) Memanfaatkan lingkungan dan arsitektur bangunan spa yang indah dan prana relaxation room serta wet facilities saat tamu menunggu jam perawatannya agar tamu tidak bosan.

4) Mempertahankan kecepatan dan keakuratan dalam reservasi, check in, check out dan pembayaran agar wisatawan tidak menunggu lama untuk menghindari komplain.

2. Strategi WO: strategi ini diterapkan berdasarkan pemanfaatan peluang yang ada dengan cara meminimalkan kelemahan yang ada. Untuk strategi pertama yakni strategi peningkatan kualitas SDM agar dapat memberikan pelayanan maksimal, berikut program - program yang dapat diterapkan adalah :

1) Melakukan pelatihan bahasa asing lain seperti Bahasa Mandarin, Bahasa Jepang dan Bahasa Korea dua (2) atau tiga (3) kali seminggu.

2) Pelatihan in house untuk skill massage dan mendatangkan trainer pelatihan produk Thalgo secara rutin ke semua terapis dan receptionist.

3) Pelatihan product knowledge dan cara menangani komplain wisatawan khususnya mengenai spa dan bekerja sama dalam pelatihan ini dengan departemen operasional lain yang biasa berhadapan dengan wisatawan.

Selanjutnya program-program yang dapat diterapkan guna menjalankan strategi penambahan paket - paket spa yang menarik dengan harga bersaing adalah sebagai berikut:

1) Lebih banyak membuat paket spa dengan harga net atau harga bersaing yang dapat dijangkau lebih banyak wisatawan.

2) Menawarkan paket spa tidak hanya pada saat ada Hari Raya besar tertentu namun membuat paket spa yang diinput dalam menu.

3) Membuat paket spa baru seperti ' $m e$ and my best friend' mengingat banyak wisatawan yang berlibur dengan teman dan sahabatnya. Selain itu paket spa seperti ' my birthday present / gift' yang bisa dibeli oleh wisatawan sebagai hadiah untuk orang terdekatnya. Paket ini dapat dikombinasikan dari perawatan massage dan facial spa dengan beauty salon serta menambahkan transport bagi outside guest.

4) Memberi potongan harga atau harga khusus jika ada wisatawan yang anniversary atau birthday. 
Program-program yang dapat diterapkan guna menjalankan strategi peningkatan promosi dan publikasi secara online maupun offline adalah sebagai berikut:

1) Promosi dengan lebih banyak foto dan video terupdate pada sosial media dan bekerja sama dengan lebih banyak travel agent, media cetak untuk publikasi offline.

2) Menambah kerja sama dengan travel agent baik dari dalam maupun luar negeri

3) Mengikuti seminar - seminar yang diadakan di dalam dan luar negeri guna lebih banyak mempromosikan The Ritz Carlton Spa.

Selanjutnya adalah strategi nilai tambah produk, program - program yang dapat diterapkan adalah :

1) Untuk menambah nilai produk agar wisatawan merasa harga yang ditawarkan pantas dengan perawatan yang diberikan, dalam perawatan 60 menit massage dapat ditambahkan complimentary wet facilities yang dimiliki oleh spa.

2) Selanjutnya bisa juga ditambah free Ritz Carlton gift seperti Ritz Carlton baseball cap atau Ritz Carlton doll (maskot Ritz Carlton) untuk minimal 2 x 60 menit massage.

3) Menambah pemandangan perawatan seperti pemadangan taman atau hutan dekat Balinese bathing pool ditambah musik angklung khas Bali.

3. Strategi ST: strategi dalam menggunakan kekuatan yang dimiliki perusahaan untuk mengatasi ancaman. Berikut program - program yang dapat diterapkan untuk Strategi lebih memperkuat brand The Ritz Carlton Spa adalah:

1) Membuat akun website dan akun sosial media khusus untuk The Ritz Carlton Spa dengan foto- foto video, dan menu - menu terupdate.

2) Menambah akun tripadvisor khusus The Ritz Carlton Spa Bali.

3) Bekerja sama dengan agen perjalanan yang digunakan oleh perusahaan perusahaan saat melakukan liburan perusahaan dengan karyawannya guna menambah penjualan dan memperkenalkan spa.

4) Menyarankan pertemuan hotel-hotel Marriot Internasional untuk mengadakan seminar khusus wellness and spa guna memperkenalkan dan mempromosikan keunikan perawatan The Ritz Carlton Spa.

Program selanjutnya untuk strategi memperkuat pangsa pasar adalah:

1) Meningkatkan pengetahuan mengenai target dan pangsa pasar seperti karakter, kesukaan, ketidaksukaan maupun bahasanya

2) Mengadakan uji kompetensi secara berkala untuk karyawan, spa terapis khususnya agar mengikuti SOP hotel guna memberikan pelayanan yang baik untuk wisatawan

Strategi penerapan harga yang dinamis atau bersaing untuk menghadapi per saingan, program - programnya adalah :

1) Memaksimalkan keunikan, complimentary beverage, spa aromatheraphy dan ketrampilan skill staff agar dapat bersaing di pasaran.

2) Mengikuti perkembangan pasar dengan memberi harga promosi - promosi tertentu se up to date mungkin

3) Memberikan harga kontrak spesial untuk agent yang lebih sering dan lebih banyak membawa wisatawan ke spa (harga yang sedikit lebih murah dari agen perjalanan lain).

4. Strategi WT: strategi ini didasarkan pada kegiatan yang bersifat defensive dan berusaha meminimalkan kelemahan yang ada serta menghindari ancaman. Strategi memperbaiki kualitas produk dan jasa agar dapat bersaing di pasaran, berikut program - program yang dapat diterapkan adalah :

1) Memperbaiki wet facilities agar selalu berfungsi dengan baik dan tidak membuat komplain wisatawan. 
2) Mempertahankan kebersihan spa khususnya area wet facilities diluar area bangunan agar selalu tampak bersih.

3) Menjaga kebersihan dan pemakaian alat-alat fitness yang lebih sering dipakai wisatawan untuk berolahraga dan arena fasilitas ini yang buka 24 jam.

Strategi meningkatkan kerjasama dan menjaga hubungan baik dengan departemen lain di hotel dan travel agent melalui online maupun offline program kerjanya adalah:

1) Mengundang dan bekerja sama dengan vlogger, youtuber atau wellness influencer dengan memberikan complimentary treatment dan sebagai gantinya harus diunggah ke akun sosial media mereka.

2) Menjaga hubungan baik dengan travel agent yang sudah lama dan baru diajak bekerja sama dengan cara seperti melakukan gathering.

3) Bekerja sama dengan travel agent melalui sosial media guna mengatasi desas desus ancaman isu Gunung Agung dengan cara membuat gambaran situasi wilayah Nusa Dua aman dari bahaya radius Gunung Agung.

\section{KESIMPULAN}

1. Lingkungan Internal dan Ekternal The Ritz Carlton Spa berdasarkan Segmentasi pasar The Ritz Carlton Spa adalah wisatawan asal Australia, Asia, Eropa, Amerika dan Afrika dan pertimbangan demografis adalah dari umur 17 tahun keatas. Target pasar yakni honeymooner lalu family guest dan group meeting atau group spa. Posisi pasar atau image yang diciptakan oleh The Ritz Carlton Spa yakni luxury spa dengan tema the source of life Bali. Bauran Pemasaran Spa dari hasil kuesioner product, process, physical evidence and payment sudah dikatakan baik. Sedangakan price, place, promotion, people and packaging masih sangat perlu ditingkatkan.

Lingkungan Eksternal berdasarkan faktor politik hukum mengenai visa, pemerintah sudah memudahkan dengan adanya visa on arrival, sosial budaya tradisi Bali yang banyak dicari wisatawan sangat membantu perumbuhan ekonomi masyarakat sekitar. Faktor teknologi yang memudahkan pemesanan serta promosi sangat menghemat biaya dan waktu, namun dengan teknologi juga harus diwaspadai komentar negatif yang dapat menjatuhkan perusahaan.

2. Strategi Pemasaran Spa

Strategi SO : Strategi menciptakan program treatment baru atau program healing berbasis tradisi budaya Bali, Strategi memaksimalkan teknologi dengan lokasi strategis, pelayanan dan proses yang cepat; Strategi WO : Strategi peningkatan kualitas SDM agar dapat memberikan pelayanan maksimal; Strategi penambahan paket - paket spa yang menarik dengan harga bersaing; Strategi peningkatan promosi dan publikasi secara online maupun offline; Strategi ST : Strategi memperkuatkan brand The Ritz Carlton Spa; Strategi memperkuat pangsa pasar; Strategi penerapan harga yang dinamis atau bersaing untuk menghadapi persaingan; Strategi WT : Strategi memperbaiki kualitas produk dan jasa agar dapat bersaing di pasaran; Strategi meningkatkan kerjasama dan menjaga hubungan baik dengan departemen lain di hotel dan travel agent melalui online maupun offline.

\section{Ucapan Terima Kasih}

Dalam pelaksanaan penyusunan laporan ini, penulis mendapat banyak bantuan, bimbingan, dan arahan dari berbagai pihak. Oleh sebab itu, dalam kesempatan ini penulis ingin menyampaikan ucapan terima kasih yang tulus kepada :

Dr. Drs. I Nyoman Sunarta, M.Si., selaku Dekan Fakultas Pariwisata Universitas Udayana. Dra. Anak Agung Putri Sri, M.Si., selaku Koordinator Program Studi Diploma IV Pariwisata Fakultas Pariwisata Universitas Udayana. Agung Sri Sulistyawati, SST. Par., M. Par, selaku Dosen Pembimbing I Laporan Akhir Program Studi Diploma IV Pariwisata Fakultas Pariwisata Universitas Udayana. Ni Ketut Arismayanti, SST, Par., M.Par., selaku Dosen Pembimbing II Program Studi Diploma IV Pariwisata Fakultas 


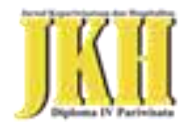

Pariwisata Universitas Udayana. I Gusti Ngurah Widyatmaja, SST. Par., M. Par., selaku Dosen Pembimbing Akademik Program Studi Diploma IV Pariwisata Fakultas Pariwisata Universitas Udayana. Putu Ratih Pertiwi, S.ST.Par., M.Par., M.Rech. dan Putu Agus Wikanatha Sagita, S.ST.Par., M.Par., selaku Dosen Penguji Laporan Akhir Diploma IV Pariwisata Fakultas Pariwisata Universitas Udayana.

Ms. Julianna Salla, selaku Director of Room The Ritz Carlton Hotel Nusa Dua. Ibu Sandra Yuanita, selaku Spa Manager The Ritz Carlton Hotel Nusa Dua yang senantiasa memberikan ijin untuk melakukan penelitian di hotel ini. Ibu Santika Armayuni selaku Spa Supervisor di The Ritz Carlton Hotel Nusa Dua yang senantiasa sebagai informan kunci dalam penelitian ini. Ibu Eveline Aprilia, selaku Spa Reception di The Ritz Carlton Hotel Nusa Dua yang senantiasa memberikan pengetahuan, arahan serta motivasi yang tidak hentinya diberikan ketika melakukan penelitian di hotel ini. Seluruh karyawan di The Ritz Carlton Spa yang senantiasa membantu memberikan informasi dan motivasi yang tidak hentinya.

\section{DAFTAR PUSTAKA}

Alma, Buchari. 2007. Manajemen Pemasaran dan Pemasaran Jasa. Bandung: ALFABETA.

Assauri, Sofjan. 2013. Manajemen Pemasaran : Dasar, Konsep dan Strategi. Jakarta: PT. Raja Grafindo.

Badan Pusat Statistik Katalog. 2017. Jumlah Akomodasi Berbintang dan Tidak Berbintang Di Provinsi Bali.

Dharmawan, Meidika Hafid. 2012. 'Peranan Strategi Pemasaran dalam Upaya Meningkatkan Penjualan Produk Jasa pada Perusahaan Jasa Pelaksana Konstruksi Cv. Meidika Jaya Di Karanganyar'. Publikasi Ilmiah

Dewa Putu Kiskenda Erwanda Putra, I Wayan Suardana, Luh Gede Leli Kusuma Dewi. 2015. 'Peran Pengalaman Sebagai Pemoderasi Pada Pengaruh Pengetahuan dan Sikap Wisatawan Mancanegara terhadap Keputusan Pembelian Produk Wellness Tourism Di Kawasan Wisata Ubud, Kabupaten Gianyar.' Universitas Udayana. Jurnal IPTA ISSN : Vol. 3 No. 1, 2015.

Kurniawan, Rian. 2016. 'Strategi Komunikasi Pemasaran Dalam Branding Hotel Lor In Syariah Surakarta (Studi Deskriptif Kualitatif Branding Hotel Lor In Syariah di Surakarta'. Publikasi Ilmiah.

Kotler, Philip. 2000. Manajemen Pemasaran: Analisa Perencanaan dan Pengendalian. Jakarta: Erlangga.

Limakrisna \& Purba. 2016. Manajemen Pemasaran (Teori dan Aplikasi dalam Bisnis). Jakarta: Mitra Wacana Media.

Morissan. 2012. Metode Penelitian Survei. Jakarta: KENCANA.

Manap, Abdul. 2016. Revolusi Manajemen Pemasaran. Jakarta: Mitra Wacana Media.

Naen, Maria Padmasanti Bunga. 2014. Landasan Konseptual Perencanaan dan Perancangan Griya Spa Di Kota Kupang. Universitas Atma Jaya Yogyakarta: Skripsi.

Noor, Juliansyah. 2011. Metodologi Penelitian. Jakarta: Kencana

Peraturan Menteri Kesehatan Republik Indonesia Nomor 8 Tahun 2014 tentang Pelayanan Kesehatan Spa.

Pramono, Jaya. 2013. 'Strategi Pengembangan Health and Wellness di Bali Fakultas Ekonomi Universitas Dhyana Pura, Bali - Indonesia. Jurnal Manajemen, Strategi Bisnis, dan Kewirausahaan Vol. 7, No. 1, Februari 2013.'

Rahadian, Dani \& Pratomo, Adithya. 2013. 'Pengaruh Bauran Promosi Terhadap Peningkatan Penjualan Kamar Di Hotel Benua Bandung.' Faculty Of Economic And Communication, Binus University. E-Business Review 
Rangkuti, Freddy. 2015. Analisis SWOT: Teknik Membedah Kasus Bisnis. Gramedia Pustaka Utama

Rambat, Lupiyoadi \& A. Hamdani. 2006. Manajemen Pemasaran Jasa. Jakarta: Salemba Empat.

Rasyiqoh, Fildzah. 2014. 'Startegi Bauran Pemasaran UMROH PT. Alia Indah Wisata.' Universitas Islam Negeri Syarif Hidayatullah. Jakarta: Skripsi.

Sudaryono. 2016. Manajemen Pemasaran (Teori \& Implementasi). Yogyakarta: C.V. ANDI OFFSET.

Sunyoto, Danang \& Susanti. 2015. Manajemen Pemasaran Jasa (Mendidik, Mengelola Dan Membidik Pasar Jasa). Jakarta: PT. Buku Seru.

Tjiptono, Fandy. 1997. Strategi Pemasaran. Yogyakarta: ANDI OFFSET.

Tjiptono, Fandy. 2015. Strategi Pemasaran Edisi- 4. Yogyakarta: ANDI OFFSET.

Utama, I Gusti Bagus Rai. 2018. Statistik Penelitian Bisnis \& Pariwisata (Dilengkapi Studi Kasus Penelitian. Yogyakarta: C.V. ANDI OFFSET.

Utama, I Gusti Bagus Rai. 2016. Pemasaran Pariwisata. Yogyakarta: C.V. ANDI OFFSET.

Wardiyanta. 2006. Metodologi Penelitian Pariwisata. Yogyakarta: C.V. ANDI OFFSET.

Wiyasa, Gede. 1997. Hotel Ramah Lingkungan Alternatif Hotel Masa Depan. Kelola. No. 16. Tahun VI, BPFE-UGM.

Yulianto, Rifqi.2014.'Analisis Strategi Pemasaran Berbasis Syariah: Pendekatan Marketing Mix (Studi Pada Hotel Grand Kalpataru Syariah Malang)'. Fakultas Ekonomi Universitas Islam Negeri (Uin) Maulana Malik Ibrahim Malang. E-Thesis.

Kusniarti, AA Seri. Usaha Terapis Spa di Bali Perlu Memiliki Sertifikasi Kompetensi. https://bali.tribunnews.com/2016/04/30/usaha-terapis-spa-di-bali-perlu-memilikisertifikasi-kompetensi. dikutip dari Tribun Bali pada 1 Agustus 2019 pukul 10 WITA.

Karana, Causa Iman. OPINI: Momentum Penting Kesinambungan Pariwisata Bali dari Pertemuan IMF-Bank Dunia.

https://finansial.bisnis.com/read/20181008/9/846697/opini-momentum-pentingkesinambungan-pariwisata-bali-dari-pertemuan-imf-bank-dunia . dikutip dari Bisnis.com pada 1 Agustus 2019 pukul 17.00 WITA.

Pertiwi F, Ni Luh Made Turis Asing di Bali Lebih Suka Menginap di Hotel NonBintang?https://travel.kompas.com/read/2016/05/27/102800227/Turis.Asing.di.Bali. Lebih.Suka.Menginap.di.Hotel.Non-Bintang. dikutip dari Bisnis.com pada 1 Agustus 2019 pukul 17.10 WITA.

Google Maps. Peta The Ritz Carlton Hotel Nusa Dua Bali https://goo.gl/maps/89u4v9463gYHGcji7 . dikutip pada 15 Juli 2019 pukul 19.45 WITA. 